\title{
KnOWledge Management IN LOCAL government: The CASE OF STEllenbosch Municipality
}

\author{
Authors: \\ Shamin Gaffoor ${ }^{1}$ \\ Fanie Cloete ${ }^{2}$

\begin{abstract}
Affiliations:
${ }^{1}$ Stellenbosch University,

${ }^{2}$ Department of Public Governance, University of Johannesburg, Johannesburg, South Africa
\end{abstract} \\ Stellenbosch, South Africa
}

Correspondence to: Shamin Gaffoor

email:

sgaffoor@sun.ac.za

\section{Postal address:}

Postgraduate \&

International Office,

Stellenbosch University,

Private Bag X1, Matieland

7602, South Africa

\section{Keywords:}

knowledge management;

local government; organisational effectiveness; public sector; Stellenbosch Municipality

\section{Dates:}

Received: 03 Feb. 2010

Accepted: 07 July 2010

Published: 16 Aug. 2010

How to cite this article: Gaffoor, S. \& Cloete, F., 2010, 'Knowledge management in local government: The case of Stellenbosch Municipality', SA Journal of Information Management 12(1), Art. \#422, 7 pages. DOI: $10.4102 /$ sajim. v12i1.422

This article is available at: http:/ / www.sajim.co.za

C 2010. The Authors. Licensee: OpenJournals Publishing. This work is licensed under the Creative Commons Attribution License.

\section{ABSTRACT}

Knowledge management (KM) was a well-founded management approach that held significant benefits for public sector organisations. KM as a management philosophy had an impact on various components of an organisation and it could therefore significantly advance organisational efficiency. The successful implementation of KM initiatives had to be ensured because, different organisational processes and departments had to collaborate and functional silos had to be eliminated. KM required long-term commitment and dedication from all organisational members. Furthermore, there were certain knowledge management enablers in an organisation that needed to be developed and that were necessary for the achievement of organisational effectiveness. These enablers were the organisational culture, human resources, information technology, organisational structure and, the organisation's strategy and leadership. This article assessed each of these enablers and how they impacted on an organisation's KM efforts. Stellenbosch Municipality was used as a case in point. The article further examined how local governments were able to effectively implement KM practices as strategic tools used to achieve service delivery and operational goals. The article concluded with a number of recommended strategies, (1) to develop the KM enablers that were present in organisations and (2) to aid the implementation of successful organisational KM initiatives.

\section{INTRODUCTION}

The demand for more efficient and effective delivery of services in South Africa has increased over recent years. In line with trends in other developing countries, South Africa has also embraced the businesslike reforms advocated by the New Public Management (NPM) school of thought, that manifests in the government's legislative prescript White Paper on Transforming Public Service Delivery of 1997 (WPTPSD). This prescript forms part of the policy document, commonly termed 'Batho Pele' ('People First' in Sotho), that reflects the customer-centric nature of South Africa's service delivery reforms and contains eight guiding principles for public sector institutions in their efforts to deliver services efficiently and effectively.

$\mathrm{KM}$ is an established management approach that has been successfully applied across corporate sectors by methodically creating, preserving and optimally using the extensive knowledge present in an organisation (Fowler \& Pryke 2003:254). The age of technology where knowledge and information serve as key strategic tools in the organisational context, creates the opportunity for local government organisations to adopt the role of knowledge-based organisations that thrive on the competence of knowledge workers. Through the implementation of KM practices, local governments could be in a position to deliver the best possible services, function effectively and operate in an environment characterised by transparency and accountability.

This article examines the question of whether the explicit implementation of a knowledge management (KM) approach in local government, the primary vehicles for the delivery of services, can enable them to meet delivery demands better. The need for efficient and effective local government services are especially urgent in South Africa.

\section{PROBLEM STATEMENT}

A considerable amount of literature about the importance of KM in the organisational context currently exists and these writings all focus on the role of KM in the corporate world. In the government sphere, not many studies have been conducted regarding KM and few have written on the role of KM in the public sector and more specifically, at local government level. It is well-known that KM offers organisations significant opportunities for innovation and change and if applied to local government, the demand for services to be delivered efficiently and effectively will be answered. The call for the adoption of new processes within municipalities will improve functionality and the quality of outputs.

In the current information age and knowledge economy, it is becoming increasingly necessary for organisations to generate and utilise information to obtain a competitive advantage and function efficiently. This notion of obtaining a competitive advantage is not necessarily relevant to the public sector, however, the process of KM has significant implications for the public sector. One of the implications is that organisations should be strategically aligned with their clients to provide better services to their clients by gaining a better understanding of their clients' needs (Fowler \& Pryke 2003:254). This implication is especially important for the public sector (municipalities), which is largely responsible for service provision to the public.

Local governments in South Africa are subjected to service delivery conditions in terms of detailed legislation set out in the Municipal Systems Act (No. 32 of 2000), the Batho Pele series of policies and 
legislative frameworks and their respective performance management indicators as stipulated in each municipality's integrated development plan (IDP) document. However, there are significant problems regarding the implementation of this policy framework at present.

\section{Research objective}

The goals of the study were, (1) to investigate the extent to which Stellenbosch Municipality demonstrates readiness for implementing $\mathrm{KM}$ practices in its organisation through the assessment of existing KM enablers present in that organisation and (2) to identify general principles demonstrated by Stellenbosch Municipality that can be used for wider application in the South African local government sphere.

\section{RESEARCH STRATEGY}

Stellenbosch Municipality is a local government organisation in the Western Cape province of South Africa, covering the municipal services rendered to Stellenbosch and the neighbouring towns of Franschhoek and Pniel. This Municipality comprises nine directorates with various sub-departments. The main role players in KM in the Municipality that were focused on in this case study were the Corporate Services, Strategic Services and Financial Services directorates.

Theoretical data were obtained through documentary assessment and empirical data were attained by means of interviews with municipal personnel present in the selected departments. The sampling procedure followed for the study was purposive (Schutt 2006:155). The aim was to determine, (1) where knowledge in the organisation is captured, (2) who is responsible for capturing knowledge, (3) by whom and how is knowledge utilised, processed and disseminated and (4) how financial, human and technological resources are employed to facilitate knowledge creation, processing, utilisation and dissemination. Six interviews were conducted on a one-onone basis with selected interviewees in different positions and departments in the organisation. Interviewees comprised senior managers and line managers from the selected departments within the Municipality. The interviews conducted were aimed at acquiring the necessary qualitative data, which primarily focused on the degree of awareness, comprehension and general acuity about KM. What also had to be determined was, (1) whether the organisational structure and strategy are conducive to effective KM, (2) whether the organisational composition supports KM and (3) to establish if the organisation's human and technological resources effectively support KM. The data analysis findings were firstly categorised into like groups.

Secondly, a comparative analysis was conducted on the data in the various groups to identify commonalities and differences in the responses generated from the interviews. Finally, the data generated from the case studies was evaluated on the basis of the theories and models identified in the literature review, in order to draw the necessary conclusions and make suitable recommendations, according to Brynard and Hanekom (1997:48).

\section{KEY CONCEPTS}

Knowledge is the key to innovation and to attaining a competitive advantage in a modern organisation (Syed-Ikhsan \& Rowland 2004a:238). The growing importance of knowledge in the organisational context has given rise to the concept of $\mathrm{KM}$. However, to comprehend the nature and value of $\mathrm{KM}$, it is important to consider what constitutes knowledge.

Morton and Lacey (2006) developed a knowledge hierarchy to illustrate the relationship between data, information, knowledge and wisdom. The knowledge hierarchy is widely used to conceptualise knowledge. It represents the idea of knowledge development in which data are converted to information and information is converted to knowledge, which then ultimately develops into wisdom (Hicks, Dattero \& Galup 2007:7). Knowledge can be described as 'applied information', meaning that knowledge is the result of information that has been processed, as each phase of the hierarchy is dependent and effected by the phase below it (Minnaar \& Becker 2005:106). It can also be said that knowledge is 'context-specific' because it is dependent on a definite period and space in time (Nonaka, Toyama \& Konno 2000:42). Two types of knowledge can be distinguished, namely tacit knowledge and explicit knowledge. Tacit knowledge refers to internalised knowledge encompassing the expertise, skills, understanding and experience within the organisation. Explicit knowledge refers to that knowledge which is readily available, documented and can be easily disseminated (Mostert \& Snyman 2007:4). Knowledge is gained from social interactions amongst individuals and within the organisation. Thus, if knowledge is not placed into context and combined with an understanding of how to utilise it, it is merely information (Hicks et al. 2007:6). The knowledge hierarchy has a few shortcomings and therefore it would be recommended to also consider Taylor's (2007:21) revised knowledge hierarchy.

The revised hierarchy provides better insight of where knowledge can be found in an organisation and how to identify it. The revised model indicates that knowledge and information predominantly presides with individuals and records are controlled on the organisational or corporate level. What can be deduced from the revised hierarchy is that the utilisation of information and records, is dependent on an individual's knowledge and skills. Knowledge is the primary element of any business process, because a tangible deliverable cannot come to pass without adequate knowledge (Taylor 2007:20). Thus, it is essential to recognise what knowledge is required to progress towards creating the information and records which invariably reveal that a business process has been concluded (Taylor 2007:20).

It is now possible to define $\mathrm{KM}$ as 'the formalisation of and access to experience, knowledge, and expertise that create new capabilities, enable superior performance, encourage innovation, and enhance customer value' (Liebowitz 1999:6). According to Fowler and Pryke (2003:254), KM involves methodically creating, maintaining and allowing access to the extensive knowledge repositories within an organisation. This allows organisations to be better suited to deliver customer services due to a greater understanding of the organisation's internal processes and functioning. These organisations are therefore able to develop and preserve the inherent knowledge of their employees, which in turn may be used to facilitate innovation and service provision (Fowler \& Pryke 2003:254).

\section{Research approach}

KM must be viewed as a process involving a number of steps and procedures. The most common steps in the KM process include knowledge generation, knowledge embodiment, knowledge sharing and knowledge utilisation (McAdam \& Reid 2000). Understanding the KM process requires one to consider the two expressions of knowledge, namely that of explicit knowledge and tacit knowledge (Mostert \& Snyman 2007:4). To conceptualise the contribution of $\mathrm{KM}$ to organisational efficiency, it is useful to consider various models of KM, which have been represented in literature on KM. KM models can be categorised in three broad categories, namely intellectual capital models, knowledge category models and socially constructed models, according to McAdam and Reid (2000:317).

The first category, the intellectual capital models aids in the conceptualisation of knowledge. According to Kong and Prior (2008:119) intellectual capital refers to the shared knowledge rooted in an organisation's staff, practices and relationship networks. The second category, the knowledge category models was devised by Nonaka and Takeuchi (1995). Knowledge 
creation refers to the continual and forceful interaction between tacit and explicit knowledge (Nonaka \& Takeuchi 1995:70). The third model is the socially constructed model, which gives a broad definition of knowledge and depicts knowledge as being inherently connected to various social and learning practices within the organisation (McAdam \& Reid 2000:317). This socially constructed model draws attention to the four main features of $\mathrm{KM}$, namely that of (1) knowledge construction in organisations, (2) the embodiment of knowledge in the organisation via social interactions, (3) the dissemination of knowledge throughout the organisation and (4) the economic use of knowledge in the organisation which may hold benefits for the employees and organisation on the whole.

KM has been identified as a philosophy that has the ability to impact on all aspects of an organisation, specifically the processes, information and communication structures in the organisation (De Gooijer 2000:303). In order for KM to contribute to organisational efficiency there is a need for various organisational processes and departments to work together and for functional silos to be eliminated. KM should also be viewed as a long-term organisational strategy (Yeh, Lai \& Ho 2006:805). KM cannot be imposed on an organisation by management, it is crucial that the initiative enjoys the support of the entire organisation in order to guarantee success.

It is essential to consider the various facets of the organisation and its subsequent impact on the KM initiative. Yeh et al. (2006:800) identified certain KM enablers in an organisation that are necessary for the achievement of organisational effectiveness. These enablers include the organisational culture, human resources, information technology and, the organisation's strategy and leadership. A thriving KM process is thus dependent on the interaction between these various organisational elements.

KM provides significant advantages for the organisation in general, such as increased performance through more efficient, productive, innovative and quality processes (Cong \& Pandya 2003:27). These advantages are reflected in more informed decision making, streamlined processes, reduced duplication, more innovation, advanced data integrity and greater cooperation within the organisation. This means that KM can contribute to cost efficiency and improved service delivery (Cong \& Pandya 2003:27). It is important to bear in mind that these advantages can only be achieved if $\mathrm{KM}$ is supported by other organisational processes, a suitable structure and an environment that is conducive to enhancing the KM process. In this regard it is thus necessary to consider the role of the four KM enablers identified by Yeh et al. (2006:800). Additionally, the impact of an organisational structure enabler on KM efforts should also be considered (Syed- Ikhsan \& Rowland 2004b:101).

\section{Data analysis of the enablers}

It is crucial for the enablers (including the organisational structure enabler) to be present and properly integrated in an organisation because the implementation of a KM effort will be easier and the organisation will consequently be able to more effectively and efficiently utilise its resources (Yeh et al. 2006:794).

\section{Organisational culture}

The organisational culture refers to the unique combination of values, beliefs and models of behaviour in an organisation. It represents the organisation's core values that dictate the behavioural norms of employees (Yeh et al. 2006:797). Thus, the manner in which people within an organisation relate to each other, especially in a group and a team situation, is important in the KM process (Lehaney et al. 2004:239). Organisational culture symbolises collective tacit knowledge, which cannot easily be taught or transferred, making it a very difficult process (Taylor 2007:30). The organisational culture epitomises both the significance and the advantages of organisational knowledge and its impact on employees' willingness to share their knowledge and provide it as valuable input into the organisation (Yeh et al. 2006:797). According to Skyrme (1999:184) an organisational culture that fosters knowledge sharing and enhancement, displays the following characteristics:

- a transparent organisational milieu

- an empowered workforce

- a dynamic learning environment

- a continual quest for novel means of development and innovation

- concentrated, transparent and extensive communication

- periods of reflection, learning and experimentation

- communication and interaction across and within groups

- objectives and performance gauges that are synchronised across the organisation

- $\quad$ an inclination toward extensive knowledge sharing among individuals who make up the workforce.

The effectiveness of KM in the organisation is restricted if an organisation has an all-inclusive KM system in place but does not have a supportive organisational culture. Thus, the real value and meaning of knowledge within a organisation only becomes apparent when it is viewed in the context of organisational culture (Lehaney et al. 2004:17).

\section{Human resources}

Knowledge is derived from an individual's use of information combined with that person's experiences. This combination is what makes individual knowledge valuable for organisations and society at large (Syed-Ikhsan \& Rowland 2004a:238). As a result, an organisation's human resources has a big impact on the organisation's KM activities.

In modern society the importance of the knowledge worker is central to any knowledge activity. The knowledge worker performs work that involves the generation of constructive information and knowledge by means of (1) accessing data, (2) personal knowledge, (3) external knowledge and (4) organisational knowledge (Sutton 2006). Knowledge workers are required to consistently utilise and convert knowledge from various sources to facilitate decision making and maintain adequate standards within the business processes (Taylor 2007:39). The contributions of knowledge workers who are prepared to build a culture conducive to KM by sharing knowledge, generating new knowledge, networking and participating in knowledge-based activities is vital to effectively execute a KM effort in an organisation (Sutton 2006). It is necessary to take into account various components of the human resources function, when considering the influence of human resources on $\mathrm{KM}$ within organisations.

During the recruitment process, most organisations specify and assess an employee's expected level of knowledge. However, employee knowledge and skills only hold value for the organisation once they are effectively applied to the employee's new position within the organisation (Taylor 2007:32). SyedIkhsan and Rowland (2004b:103) identify posting, training and staff-turnover as key criteria to consider in this regard. In terms of posting, Syed-Ikhsan and Rowland (2004b:103) argue that employees' past experiences, skills and qualifications are valuable to an organisation and when employees are placed in the right position within an organisation, it is to be expected that new knowledge will be generated effortlessly. Despite existing employee knowledge and skill, employees are able to gain valuable knowledge from induction and training programmes (Taylor 2007:33). Adequate training allows employees to transfer their knowledge into the organisation's practices, processes, policies and traditions (Syed-Ikhsan \& Rowland 2004b:103). Training and learning programmes thus make favourable contributions to an organisation's human capital in the long run (Taylor 2007:34). High staff turnover also poses problems for KM in that vital organisational knowledge may be lost in the event 
of employees retiring or moving on to other positions. Therefore, organisations should implement people-centred KM strategies that foster learning, encourage sharing through motivation and teamwork and allow employees ample time to learn and reflect on their knowledge (Skyrme 1999:54).

\section{Information technology}

Information technology is central to the maintenance and organisation of KM efforts (Yeh et al. 2006:799). According to Yeh et al. (2006:799) information technology supports KM by facilitating quick searching, access to and retrieval of information, which in turn encourages cooperation and communication between members of an organisation.

Various information technology tools are available to organisations to aid effective KM (Syed-Ikhsan \& Rowland $2004 \mathrm{~b}: 102)$. The group of information technology tools that are utilised for the purpose of KM are known as KM systems (Alavi \& Leidner 2001:114). When an organisation considers employing a specific KM tool it is necessary to do an analysis of the organisation and its current systems in order to determine which tool would be the most effective in facilitating the organisation's requirements (Taylor 2007:60). It is also important to know how the tool will be integrated with current systems and what degree of staff training and development would be required upon implementation of the tool (Taylor 2007:60). Only when the worth of the tool is established and its value is overtly recognised, then it is most likely that it will be successfully utilised (Taylor 2007:61).

\section{Organisational structure}

Organisational structure may be defined as the manner in which individuals and posts are organised to make the performance of the organisation's work possible (Syed-Ikhsan \& Rowland 2004b:101). Nonaka (1994:30) argues that a top-down bureaucratic structure is not conducive to the process of creating knowledge within an organisation, as only top management have the power and ability to create information which they use as a mere tool instead of a tangible product. Conversely, in a bottom up organisational model only lower-level and middlelevel employees are responsible for knowledge creation, which is also not favourable. What is required, however, is a model that takes into account all organisational members who work together collectively to generate knowledge. This means that no particular department or group has the sole responsibility for knowledge generation. The organisational structure must therefore promote communication across and within organisational boundaries and strengthen interdependence of teams and networks (Skyrme 1999:185). Thus it is imperative that when an organisation embarks on a KM strategy, it realigns its organisational structure to facilitate the creation and effective flow of knowledge throughout the organisation.

\section{Strategy and leadership}

The implementation of a KM effort requires an organisation strategy that is based on contributions by various members of the organisation (Yeh et al. 2006:795). Deriving from the organisation's strategy are the various organisational policies and programmes. These policies and programmes must be aligned with each other and should be mutually supportive of an organisation's KM strategy (McElroy 2003:60).

Related to a KM strategy, is the concept of leadership. The implementation of a KM effort requires adequate support and dedication from top management as this influences how resources and time are allocated for executing the KM plan (Yeh et al. 2006:797). A successful KM strategy therefore runs parallel with exemplary leadership that values 'trial and error' and shows a commitment to innovation and continuous improvement (Rylatt 2003:5)

An effective KM strategy thus requires, (1) long-term commitment from all organisational members, (2) the ability to be receptive to changes in both the internal and the external organisational environment and (3) leadership that demonstrates an enthusiasm for improvement. Furthermore, an effective KM strategy must take advantage of knowledge-enabling technological developments to allow the organisation to be more responsive in terms of service provision and developing relationships (Skyrme 1999:33).

\section{Knowledge management in the public sector}

Most examples of KM applications can be found in the private sector, which utilises the KM process as a means of attaining a competitive edge (Fowler \& Pryke 2003:255). The manifestation of $\mathrm{KM}$ within the public service sector, albeit not unheard of, is less prevalent (Fowler \& Pryke 2003:255). However, as governments are adopting policies that recognise the 'information age', there is a stronger inclination toward $\mathrm{KM}$ within the government sphere (Fowler \& Pryke 2003:255).

Considering the reforms within the public sector over the past few decades, it is evident that most public sector organisations now follow a businesslike approach where the focal point of service provision is responding to citizen needs and providing integrated and comprehensive service delivery (Fowler \& Pryke 2003:258). Consequently, the public sector is accommodating the KM concept as a means of attaining a competitive edge, by using the human and intellectual resources within their organisations (Fowler \& Pryke 2003:258)

KM has a number of benefits for public sector organisations. Cong and Pandya (2003:27) have identified these benefits as follows:

- $\mathrm{KM}$ creates the opportunity for employees to develop their skills, performance and experience through group work and knowledge sharing.

- KM improves organisational performance by means of better quality, innovation, productivity and efficiency.

- KM facilitates better decision making, more collaboration restructuring of organisational processes and a decline in the duplication of work, consequently cutting operational costs and improving service delivery.

- KM increases the financial worth of an organisation.

- Knowledge sharing creates value in an organisation and strategically enables a competitive advantage.

The significance of KM for the public sector is apparent, many public sector organisations have shown disinclination toward exploring what KM has to offer for their organisations (Edge 2005:43). According to Cong and Pandya (2003:25) there is a need for increased KM awareness among managers and lower-level personnel in the public sector. Given the many benefits associated with KM in the public sector, several factors discourage public sector KM efforts. These include the sheltered nature of most public sector work, the need of employees to preserve and guard their personal knowledge and the continual cut-backs on centrally allocated resources (Edge 2005:42).

$\mathrm{KM}$ is receiving increased priority within the context of the South African public sector. The Department of Provincial and Local Government (Republic of South Africa 2007) has identified KM as a key managerial skill for senior managers at local government level. This requirement involves the ability to advance knowledge creation and sharing as a means of developing the combined knowledge of the local government (Republic of South Africa 2007).

Emphasis has been placed on managerial KM competencies but not enough prominence is given to the need for an organisation-wide implementation of KM systems. Initiatives by the South African government to propel KM practices within government organisations include the establishment of a Knowledge Information Management (KIM) work group within the Government IT Officers (GITO) council. According 
to GITO (2004) there are already a number of KM practices within government departments. However, these practices are not all-inclusive of $\mathrm{KM}$ processes, which are required for further development. The Department of Public Service and Administration has also recognised the need to put KM into operation within government departments (Matomela 2008). This department is subsequently cultivating a culture of knowledge sharing by means of 'internal learning sessions', where knowledge is exchanged among employees through a number of modes such as newsletters, web pages and discussion boards. Other means of employing KM initiatives and cultivating a sharing culture include, (1) the compilation of knowledge registers in which knowledge and skills are recorded, (2) capacity-building initiatives and harvesting and (3) effectively utilising internal employee skills as opposed to external hired or consultants' skills (Matomela 2008).

At local government level, cognisance must be taken of the fact that South African municipalities function in a milieu characterised by greater uncertainty and competition than in the past. Local government institutions across the globe are faced with demands to change and modernise their operations so as to facilitate development in the new 'knowledge economy' (Haricharan 2004). To keep abreast of these changes and to remain globally competitive, South African local governments need to become aware of the significance of KM in achieving organisational and subsequent service delivery successes.

\section{DISCUSSION AND RESULTS}

The accumulated data were assessed to determine the organisation's position in relation to Yeh et al.'s (2006) proposal of the relationship between KM enablers and organisation effectiveness. The aim of the analysis was to determine any patterns or trends based on the interview subjects' responses to a series of questions centred on the four key components of the organisation.

The senior managers' responses to the question regarding their awareness and comprehension of KM were analysed in terms of their answers in the context of Liebowitz's (1999:6) definition of KM. The research indicated that the concept of KM is still an indistinct and novel idea among senior personnel members of Stellenbosch Municipality and that a greater awareness of its importance and subsequent benefits needs to be instilled among senior managers.

\section{Data analysis of the enablers}

\section{Organisational culture}

The current organisational culture shows potential for developing into a thriving culture that can sustain the implementation and functioning of KM efforts, according to the interviews that were conducted. By observing the culture present in each of the assessed departments, it is evident that there is a willingness to share information and a proclivity toward the implementation of KM efforts. Knowledge sharing is widespread in the organisation but they still face the challenge of fully implementing KM. The culture of information and knowledge sharing is reasonably established but a culture persists with regard to a lack of enthusiasm to learn how to utilise technologies and information. As a consequence, what is required is the means to clarify to staff members what benefits knowledge sharing and management hold and to encourage a change in their approach to dealing with information and knowledge.

A culture of knowledge sharing is present and thriving, although it is only within the boundaries of each department. There is a certain degree of communication and an exchange of information between the departments, although it seems that all the departments essentially operate in functional silos. Despite the apparent culture of sharing, the overall organisational culture is still one of hesitation in terms of sharing across departments. This can largely be attributed to a general lack of understanding of $\mathrm{KM}$ and related concepts, as well as a lack of trust among employees.

\section{Human resources}

Stellenbosch Municipality adheres to stipulated recruitment and selection procedures and adequate training and skills development initiatives. All employee appointments are carried out in accordance with a set of predefined requirements regarding skills and competencies. The municipality functions in a political milieu which also influence employee placements.

The municipality's human resources management is effective and employees are geared toward embracing KM initiatives. Employee capacities are developed via training and development programmes administered by theSkills Development department within the Human Resources department. Continuous efforts are made to ensure that employee placements are in accordance with employee competencies, skills and qualifications, as well as the technical requirements and job descriptions.

The incidence of high staff turnover is problematical in terms of $\mathrm{KM}$, in that fundamental organisational knowledge may be lost when employees retire or are promoted. The municipality has a low employee turnover rate, which is conducive to KM as it encourages learning and enables the retention of tacit knowledge and the transfer of knowledge. However, notwithstanding the importance of developing and recruiting personnel internally, the need always exists to recruit external personnel who bring new skills and ideas to the organisation.

\section{Information technologies}

Stellenbosch Municipality has various contemporary information technology systems in place. However, the municipality utilises various systems in various departments, thus there is no single system spanning over the entire municipality. As these systems are not integrated, information sharing is hampered and accessibility to information sources are limited. The municipality has a strong information technology platform and support network. The Municipality runs a number of information and content management systems in various departments. These include the South African Municipal Resource Administration System (SAMRAS), which is a financial system, Collaborator, which is a document management system and ValueProp, which is used for property valuations and related information. The municipality also runs a Geographic Information System (GIS) (Fourie 2007). In addition, the organisation operates a database known as the Strategic Management System (SMS), which is used to capture all information and data related to the municipality's budget and integrated development plan (IDP). An e-library has also been established, where personnel members have access to a number of documents including relevant policies and legislation (Fourie 2007). The municipality also runs a useful website, from which GIS information, the e-library and other administrative information is available. This includes notices, job vacancies and links to council and staff members.

Stellenbosch Municipality possesses an adequate information technology infrastructure to facilitate any KM efforts. However, there is room for improvement and the need exists to implement an organisation-wide information system. This would allow for easy access to and retrieval of information and knowledge in various parts of the organisation.

\section{Organisational structure}

The municipality has a top-down, hierarchical organisational structure, which is not the most conducive to KM efforts, in that it is characterised by a bureaucratic nature and thus it is not very responsive to changes being made. Furthermore, it is also a 
deterrent to horizontal communication flows. Skyrme (1999:32) claims that the network structure is most suitable to facilitate KM. The network structure consists of virtual teams and organisations that permit the organisation to generate greater value via a variety of unique skill combinations that may be flexibly pooled when required (Skyrme 1999:33). The networked organisation is thus more adaptable and allows for a more rapid response to changes.

\section{Strategy and leadership}

Stellenbosch Municipality's IDP comprises the organisation's strategy. It is a strategic plan that displays the organisation's vision and mission and serves as a road map to show where the organisation is and where it is headed.

It is clear that the Municipality does not have a formalised KM strategy in place yet. The strategic services department is thus far the only department that has created a position for a KM officer within their departmental microstructure. Efforts are underway to establish a KM unit within the municipality's corporate services directorate (Fourie 2007).

The implementation of a KM effort requires adequate support and dedication from top management as this influences how resources and time are allocated for the successful execution of the KM plan (Yeh et al. 2006:797). It was clear from the interviews with the senior personnel in the four departments that the greatest challenge to $\mathrm{KM}$ is the acceptance of the concept by the organisation's leadership which are made up of council members and top management. The acceptance and support of the organisation's leadership was mentioned in all the interviews as the biggest constraint to KM, largely due to the lack of knowledge concerning KM. Unless the organisation's leadership are committed to and support KM efforts, any successful attempt at KM will be futile.

\section{CONCLUSION}

Stellenbosch Municipality has the potential to implement a successful KM initiative. Apart from the need for some improvements, the human resources and the information technologies available are all conducive to $\mathrm{KM}$ to some extent. The greatest challenge facing the municipality in terms of becoming a knowledge organisation and achieving organisational effectiveness is attaining leadership support and establishing a sharing culture across the municipality. Once top management supports the concept and the organisational culture acknowledges the importance of KM, then Stellenbosch Municipality can plan and strategise in terms of its KM initiative.

\section{RECOMMENDATIONS}

If the municipality wants to become a knowledge-based organisation and ultimately achieve organisational effectiveness, it first has to devise an explicit KM strategy. All the KM enablers are present at the municipality, but what is required is to identify the key aspects of these enablers that need to be developed in order to make them more beneficial to KM efforts. The KM strategy should be tactically aligned with the organisation's overall strategy (i.e. municipality's IDP document). The KM strategy should be used as a plan to highlight the organisation's goals in terms of KM. The strategy must take into account the organisation's resources and needs must be identified. The strategy should also contain an outline of how to attend to these needs and provide suitable solutions. A good KM strategy requires enthusiasm and continuing commitment from all organisational members. In particular, both the leadership and the strategy must be flexible and adaptable to changes in the organisation's milieu.
The second recommendation is to build an organisational memory (also known as a knowledge repository). Building an organisational memory involves pooling and streamlining the entire organisation's reports and documents and extracting further information from these reports, such as lessons learned and best practices to follow. These documents should be made available electronically and should be easily accessible from a single point of access (Lehaney et al. 2004:238). To establish a successful knowledge repository, it is essential to learn how to locate knowledge and strategically place it in the organisation to be available when it is needed.

The third recommendation is to reward employees and create incentives for contributions to knowledge generation, sharing and management. It is important to create an environment and culture to facilitate KM and to establish communities of practice. This type of culture must be driven by dynamic leadership and ultimately produce what is known as 'knowledge workers'. Since a sharing culture is crucial to an effective KM strategy, the municipality should look into devising an incentive structure for employees' KM efforts.

The fourth recommendation is to actively implement a KM division within the organisation. It is important to create an independent department or a position housing a chief knowledge officer to oversee, manage and drive the organisation's KM activities. The KM division should not only be responsible for the technological aspects of KM and for managing the organisation's knowledge resources, but it should also constantly strive to take advantage of opportunities for innovation and to establish communities of practice both within the Municipality and with parties outside the municipality's immediate environment. A separate KM division will result in the municipality's ability to deliver better services, based on, better utilisation and dissemination of knowledge.

The KM division should also be responsible for devising a KM governance policy that is aligned with and mutually supportive of the KM strategy. According to Zyngier, Burstein and McKay (2004:892) governance refers to a means of regulation by utilising a framework to guarantee the delivery of the possible advantages associated with a project or service. A KM governance policy thus serves not only as the framework for the scrutiny and management of KM processes, but also as a means to gauge the effectiveness of the KM strategy.

KM has become a vital part of modern business management and equally so, of modern public sector management. KM offers local government organisations a vast array of benefits, including enhanced service delivery, productivity, decision making and efficiency.

Before a KM initiative is implemented it is essential to ensure that certain enablers are present and adequately developed within an organisation. These enablers that include the organisation's culture, human resources, strategy and leadership, information technologies and organisational structures are not exclusive but interdependent. Thus, for an organisation to implement a successful KM initiative and attain organisational efficiency, each of these enablers must be adequately developed and be supportive of each other.

The above conclusion and recommendations about the conditions to facilitate effective KM utilisation in Stellenbosch Municipality are also basic conditions for other local government organisations.

\section{REFERENCES}

Alavi, M. \& Leidner, D.E., 2001, 'Review: KM and KM Systems: Conceptual foundations and research issues', MIS Quarterly 25(1), 107-136.

Brynard, P.A. \& Hanekom, S.X., 1997, Introduction to research in public administration and related academic disciplines, J.L Van Schaik, Pretoria. 
Cong, X. \& Pandya, K., 2003, 'Issues of KM in the public sector', Electronic Journal of Knowledge Management 1(2), 25-33.

De Gooijer, J., 2000, 'Designing a KM performance framework', Journal of Knowledge Management 4(4), 303-310.

Edge, K., 2005, 'Powerful public sector KM: A school district example', Journal of Knowledge Management 9(6), 42-52.

Fowler, A. \& Pryke, J., 2003, 'KM in public service provision: The child support agency", International Journal of Service Industry Management' 14(3), 254-28.

Haricharan, S., 2004, KSP hologram newsletter 3: KM in the South African public sector, viewed 27 September 2007, from http:/ / www.ksp.org.za/holonl03.htm.

Hicks, R., Dattero, R. \& Galup, S.D., 2007, 'A metaphor for KM: explicit islands in a tacit sea', Journal of Knowledge Management 11(1), 5-16.

Kong, E. \& Prior, D., 2008, 'An intellectual capital perspective of competitive advantage in nonprofit organisations', International Journal of Nonprofit and Voluntary Sector Marketing 13, 119-128.

Lehaney, B., Clarke, S., Coakes, E. \& Jack, G., 2004, Beyond KM, Idea Group Publishing, Hershey.

Liebowitz, J. (ed.), 1999, Knowledge Management handbook, CRC Press, Boca Raton

Matomela, B., 2008, Public service wide KM programme. SA Cities Network / SALGA KM Workshop. East London, 7 February 2008.

McAdam, R. \& Reid, R., 2000, 'A comparison Of public And private sector perceptions and use of Knowledge Management', Journal of European Industrial Training 24(6), 317-329.

McElroy, M.W., 2003, The new Knowledge Management: Complexity, learning, and sustainable innovation, Butterworth-Heinemann, Burlington.

Minnaar, F. \& Bekker, J.C.O., 2005, Public management in the information age, Van Schaik, Pretoria.

Morton, G. \& Lacey, M., 2006, Embracing Knowledge Management: A local government study, IDOX, London.

Mostert,J.C. \& Snyman, M.M.M., 2007, 'Knowledge Management framework for the development of an effective Knowledge Management strategy', South African Journal of Information Management 9(2).

Nonaka, I., 1994, 'A dynamic theory of organisational knowledge creation', Organisation Science 5(1), 14-37.

Nonaka, I. \& Takeuchi, H., 1995, The knowledge-creating company: How Japanese Companies Create the Dynamics of Innovation. Oxford University Press, New York.

Nonaka, I., Toyama, R. \& Konno, N., 2000, 'SECI Ba and leadership: a unified model of dynamic knowledge creation', in S. Little, P. Quintas \& T. Ray (eds.), 2002, Managing knowledge: an essential Reader, Sage Publications Ltd, London.
Republic of South Africa, 1997, White paper on transforming public service delivery: Batho Pele - "People First", Department of Public Service and Administration, viewed 15 October 2006, from http://www.polity.org.za/html/govdocs/white_ papers/transform.html.

Republic of South Africa, 2000, Local government: Municipal Systems Act No. 32 of 2000, Government Gazette No. 21776, 20 November, Government Printers, Pretoria.

Republic of South Africa, 2007, Managerial competency framework for senior (section 57) management at local government, Department of Provincial and Local Government, viewed 05 January, from http://www.dplg.gov.za/documents/ generaldocument/Guidelines_competency_framework_ and_profiles_Appendix_B.doc.

Rylatt, A., 2003, Winning the knowledge game: Smarter learning for business excellence, Butterworth-Heinemann, Oxford.

Schutt, R.K., 2006, Investigating the social world: The process and practice of research, 5th edn., Pine Forge Press, Thousand Oaks.

Skyrme, D., 1999, Knowledge networking: Creating the collaborative enterprise, Butterworth-Heinemann, Oxford.

South African Government IT Officers Council, 2004, 'Developing a government knowledge and information management (KIM) strategy', Discussion document draft 1.2, July, 2004.

Sutton, M., 2006, 'Why we need knowledge workers to become knowledge citizens', South African Journal of Information Management 8(1).

Syed-Ikhsan, S.O.S. \& Rowland, F., 2004a, 'Benchmarking KM in a public organisation in Malaysia', Benchmarking: An International Journal 11(3), 238-266.

Syed-Ikhsan, S.O.S \& Rowland, F., 2004b, 'KM in a public organisation: A study on the relationship between organisational elements and the performance of knowledge transfer', Journal of Knowledge Management 8(2), 95-111.

Taylor, L., 2007, Knowledge, information and the business process: Revolutionary thinking or common sense?, Chandos Publishing Limited, Oxford.

Welman, C., Kruger, F. \& Mitchell, B., 2006, Research methodology, 3rd edn., Oxford University Press, Cape Town.

Yeh, Y., Lai, S. \& Ho, C., 2006, 'Knowledge Management enablers: A case study', Industrial Management and Data Systems 106(6), 793-810.

Zyngier, S., Burstein, F \& McKay, J., 2004, KM governance: A multifaceted approach to organisational decision and innovation support, Monash University School of Information Management and Systems, Melbourne, viewed 2 August 2008, from http://s-cah-vishnu.infotech.monash.edu.au/ dss2004/proceedings/pdf/87_Zyngier_Burstein_McKay. pdf. 